\title{
Estimating Overnight Weight Loss of Corralled Yearling Steers in Semiarid Rangeland
}

\author{
By Justin D. Derner, Justin L. Reeves, Matthew C. Mortenson, Mark West, \\ J. Gonzalo Irisarri, and Martin Durante
}

\section{On the Ground}

- A common practice for assessing livestock weight gains from grazing animals on rangelands is to confine animals overnight without feed or water to reduce variation in weight loss and percent shrink.

- Advances in remote sensing of vegetation, such as the Normalized Difference Vegetation Index (NDVI) provide opportunities to estimate greenness (an indicator of both the quality and quantity of the plant community) that could be used with air temperature and relative humidity as predictors of percent shrink in grazing animals.

- We determined percent shrink losses from crossbred yearling steers at each of four weigh dates for four consecutive years.

- Percent overnight shrink by yearling steers grazing semiarid rangeland was influenced positively by air temperature and NDVI values, but not relative humidity.

- The prediction equation we developed can provide temporal weight gain data within a grazing season without the logistical difficulties in gathering and holding animals, as well as eliminate associated animal stress from shrinking and regaining gut fill multiple times.

Keywords: air temperature, overnight shrink, relative humidity, remote sensing, shortgrass steppe.

Rangelands 38(3):101-104

doi: $10.1016 /$ j.rala.2016.02.004

(C) 2016 The Society for Range Management

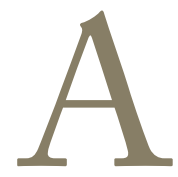

common practice for assessing livestock weight gains from grazing animals on rangelands is to confine animals overnight without feed or water to reduce variation in gastro-intestinal (gut) fill, which can represent $10-22 \%$ of pre-shrunk body weight. ${ }^{1,2}$ Other common weighing protocols include only withholding feed, weighing animals on multiple, consecutive days, and weighing animals at the same time each day. There is a need for a standard procedure that is less labor intensive and more animal friendly. Percent animal weight lost during this overnight period ranges from $2.3-5.9 \%$ of total body mass over 12 hours for steers on rangeland. Environmental influences associated with weather conditions, such as humidity and temperature, can affect shrink for cattle grazing on rangeland. ${ }^{3-5}$

Advances in remote sensing of vegetation provide opportunities to estimate greenness that could be used as another predictor of percent shrink in grazing animals. The Normalized Difference Vegetation Index (NDVI) is a broadly applied remotely-sensed spectral index that integrates two key spectral features of vegetation: 1) low reflectance in the red wavelengths, and 2) high reflectance in the infrared portions of the electromagnetic spectrum. It is calculated as: NDVI = (IR-R $)$ / $(\mathrm{IR}+\mathrm{R})$, where $\mathrm{R}$ is the reflectance in the red portion of the electromagnetic spectrum and IR is the reflectance in the infrared portion. Values range from 0 to 1 , with low values (e.g., 0.1) representing bare ground and higher values (e.g., 0.8) representing active growing vegetation. NDVI has been directly related to aboveground forage production ${ }^{6}$ and forage quality ${ }^{7}$ in the North American Great Plains.

Understanding the influence of NDVI, in addition to environmental factors, on percent shrink for grazing animals could provide an acceptable alternative to traditional production practices by offering a practical and reliable method for estimating weight losses from overnight shrink on cattle grazing rangelands across the grazing season. This would allow for quantitative temporal gain measurements without the associated stress of the shrink and regaining gut fill for grazing animals following each weigh date. Cattle would only need to be gathered and weighed immediately (i.e., unshrunk weights), and then placed back on pasture. Alternatively, non-shrunk cattle weights could even be obtained automatically from scales within pastures ${ }^{8,9}$ and weights adjusted using determined prediction equations derived from experimental studies. 
The objective of our study was to quantify overnight percent shrink losses for yearling steers grazing semiarid rangeland, and to determine if environmental variables (e.g., relative humidity and temperature) and vegetation qualities (e.g., NDVI index) influenced these percent shrink losses across the summer grazing season. We determined percent shrink losses from crossbred yearling steers at each of four weigh dates (June, July, August, and September) for four consecutive years (2009-2012). We hypothesized that percent overnight shrink would be increased by higher air temperatures, lower relative humidity, and higher NDVI values (indicative of greener vegetation conditions).

\section{Study Location and Methods}

The USDA-Agricultural Research Service Central Plains Experimental Range is located about $20 \mathrm{~km}$ northeast of Nunn, in north-central Colorado, USA ( $\left.40^{\circ} 50^{\prime} \mathrm{N}, 104^{\circ} 43^{\prime} \mathrm{W}\right)$. Mean annual precipitation is $341 \mathrm{~mm}$, and mean May-September precipitation is $240 \mathrm{~mm}$. Precipitation values for May-September during the study years ranged from $36 \%$ below the mean (153 $\mathrm{mm}$ in 2012) to $18 \%$ above (283 $\mathrm{mm}$ in 2009), with 2010 slightly below average $(206 \mathrm{~mm})$ and 2011 average $(239 \mathrm{~mm})$. Topography in the pasture for this study is mostly gently undulating plains. Native vegetation is dominated by the perennial $\mathrm{C}_{4}$, shortgrasses blue grama [Bouteloua gracilis (Willd. ex Kunth) Lag. ex Griffiths] and buffalograss $[B$. dactyloides (Nutt.) J.T. Columbus], perennial $\mathrm{C}_{3}$ midheight grasses western wheatgrass (Pascopyrum smithii [Rydb] A. Love), and needle-and-thread (Hesperostipa comata [Trin. \& Rupr.] Barkworth ssp. comata), and needleleaf sedge (Carex duriuscula C.A. Mey) is another important perennial $\mathrm{C}_{3}$ graminoid. Scarlet globemallow (Sphaeralcea coccinea [Nutt.] Rydb.) is the primary forb and plains pricklypear (Opuntia polyacantha Haw) is frequent. ${ }^{10}$ Mean annual aboveground plant production is $750 \mathrm{~kg} / \mathrm{ha} .{ }^{11}$

Twenty yearling crossbred steers in a long-term (since 1939) moderately grazed (0.65 Animal Unit Months, AUM/ha) 129.5 ha pasture, ${ }^{10}$ were gathered and weighed four times at 28-day intervals (i.e., weigh dates) in each of four grazing seasons (2009-2012) for a total of 16 weighings across the study. Grazing seasons started in mid-May and continued to late September/early October each year. Steers were gathered beginning at 3:00 PM using low-stress animal handling techniques, ${ }^{12}$ and gathering was completed within one hour because gathering time has significant impact on shrink of grazing cattle. ${ }^{13}$ The weighing facility was directly adjacent to the study pasture. Immediately after gathering, steers were individually weighed using low-stress animal handling techniques. ${ }^{12}$ The 20 steers were then held overnight without feed or water in a corral (i.e., drylot holding pen) with an area of $149 \mathrm{~m}^{2}$, giving each animal approximately four times the industry standard of $1.9 \mathrm{~m}^{2}$ per animal. ${ }^{14}$ Steers were again individually weighed beginning at 8:00 AM the next day, or 17 hours following initiation of gathering. All animal protocols were approved by the Central Plains Experimental Range Institutional Animal Use and Care committee. No significant adverse consequences were observed in any animals related to the confinement period regarding health problems and/or excessive distress related to food and water deprivation. Percent shrink was calculated as:

$\frac{(\text { non-shrunk weight }- \text { shrunk weight })}{\text { non-shrunk weight }} \times 100$

Environmental variables used to test for effects on percent shrink were: 1 ) average relative humidity (\%), and 2) average air temperature $\left({ }^{\circ} \mathrm{C}\right)$ values calculated from averaging hourly means for the entire overnight shrink period. Environmental variables were calculated from 2:00 PM (1 hour prior to gathering) to 8:00 AM the following morning (weighing time), and were obtained from a weather station located $4 \mathrm{~km}$ east of the weighing facility. We obtained NDVI values from the MODIS project (Collection 5 of MOD13Q1, Vegetation Indices product, gridded, 16 -day composite images with $250-\mathrm{m}$ pixel size $\left.^{\mathrm{i}}\right)$. We extracted all NDVI values of the MODIS pixels completely contained in the pasture. For each weigh date, we used linear interpolation to determine the NDVI value using the two closest dates of NDVI data.

To test for effects of environmental (weather) variables and NDVI values on percent shrink, we used multiple regression models in the statistical analysis program JMP 10.0.0 (SAS Institute Inc., Cary, NC, USA). Percent shrink values used were means calculated from the 20 steers for each of the 16 weigh dates. Analyses with individual steer values had the same model results but fit of the models (amount of variance explained) was less robust. Effects of average relative humidity and average air temperature during the holding period, and interpolated NDVI values for the weigh date (Table 1) were included in the models. Multiple possible models were examined, and the best, most descriptive/predictive model (presented below) was considered to be the one with the lowest Akaike Information Criterion (AIC) value.

\section{Environmental Conditions}

Among the four study years (16 weigh dates), relative humidity and average temperature exhibited high variability (Table 1). For example, relative humidity ranged four-fold from a low of $21 \%$ on 14 June 142012 , to a high of $89 \%$ on 12 June 2009. Average air temperatures ranged greater than two-fold with a low value $\left(9.9^{\circ} \mathrm{C}\right)$ observed on 12 June 2009 , and a high value $\left(22.6^{\circ} \mathrm{C}\right)$ on 12 August 2010. Other weigh dates where average temperatures exceeded $21.5^{\circ} \mathrm{C}$ included 5 August 2009, 1 September 2011, and the first three weigh dates in 2012 (14 June, 12 July, and 9 August).

\section{NDVI Values}

NDVI values were generally greater earlier in the grazing season and then decreased as the grazing season progressed (Table 1). Greatest NDVI values (0.6) occurred in the wettest year (2009), and very low values (0.2) were observed in the

\footnotetext{
i For more information on the MODIS project, see http://modis.gsfc. nasa.gov/data/dataprod/mod13.php.
} 
Table 1. Weather conditions, yearling steer pre-shrink weights $(\mathrm{kg})$, and percent steer shrink values during the 4-four year study period (20092012; 16 total weighings) at the USDA-ARS Central Plains Experimental Range, Nunn, CO, USA

\begin{tabular}{|c|c|c|c|c|c|c|}
\hline Year & Weigh date & $\begin{array}{l}\text { Relative } \\
\text { humidity } \\
(\%)\end{array}$ & $\begin{array}{l}\text { Average } \\
\text { temperature } \\
\left({ }^{\circ} \mathrm{C}\right)\end{array}$ & $\begin{array}{l}\text { NDVI } \\
\text { value }\end{array}$ & $\begin{array}{l}\text { Pre-shrink } \\
\text { weight }(\mathbf{k g}) ; \\
\text { mean }( \pm \mathrm{SD})\end{array}$ & $\begin{array}{l}\text { Percent } \\
\text { shrink; } \\
\text { mean }( \pm S D)\end{array}$ \\
\hline \multirow[t]{4}{*}{2009} & June 12 & 88.9 & 9.9 & 0.602 & $318.1(35.7)$ & $9.1(1.1)$ \\
\hline & July 9 & 62.2 & 19.4 & 0.522 & 364.2 (38.5) & $10.5(1.0)$ \\
\hline & August 5 & 60.5 & 21.6 & 0.385 & $396.2(40.0)$ & $9.4(0.7)$ \\
\hline & September 3 & 53.8 & 16.8 & 0.288 & $399.7(36.6)$ & $6.5(0.9)$ \\
\hline \multirow[t]{4}{*}{2010} & June 18 & 49.9 & 16.3 & 0.527 & $356.8(21.6)$ & $9.6(1.4)$ \\
\hline & July 15 & 71.5 & 17.6 & 0.416 & $396.4(22.6)$ & $8.9(1.0)$ \\
\hline & August 12 & 33.8 & 22.6 & 0.311 & $425.1(24.5)$ & $9.3(1.0)$ \\
\hline & September 9 & 64.3 & 15.8 & 0.219 & $434.6(24.6)$ & $6.9(0.8)$ \\
\hline \multirow[t]{4}{*}{2011} & June 9 & 72.6 & 13.9 & 0.416 & $331.2(25.6)$ & $8.9(0.9)$ \\
\hline & July 7 & 83.3 & 17.8 & 0.362 & $370.3(27.2)$ & $7.3(1.9)$ \\
\hline & August 4 & 66.8 & 19.9 & 0.296 & 399.4 (23.5) & $8.2(1.1)$ \\
\hline & September 1 & 38.5 & 22.1 & 0.250 & $429.7(22.0)$ & $8.7(1.1)$ \\
\hline \multirow[t]{4}{*}{2012} & June 14 & 21.3 & 22.5 & 0.215 & $331.4(28.5)$ & $7.4(0.9)$ \\
\hline & July 12 & 48.3 & 22.3 & 0.246 & $352.0(29.8)$ & $8.2(0.8)$ \\
\hline & August 9 & 32.1 & 22.5 & 0.233 & $377.3(28.7)$ & $9.2(0.7)$ \\
\hline & September 6 & 25.7 & 15.9 & 0.221 & 397.4 (31.0) & $6.2(0.8)$ \\
\hline
\end{tabular}

Average temperature $\left({ }^{\circ} \mathrm{C}\right)$ and relative humidity (\%) values represent averaged hourly means from 2:00 PM1400 hours (1 hour prior to gathering) to 8:00 AM0800 hours (weighing time the following morning). Normalized Difference Vegetation Index (NDVI) values (Collection 5 of MOD13Q1, Vegetation Indices product, gridded, 16-day composite images with 250-m pixel size, http://modis.gsfc.nasa.gov/data/dataprod/mod13.php) represent linear interpolations for the weigh dates.

drought year of 2012. NDVI values in 2012 were smaller than any other observed value across the other 3 years with the exception of the value (0.219) observed on 9 September 2010.

\section{Effects on Overnight Shrink}

Across the 16 weighings, percent overnight shrink ranged from $6.2 \%$ (6 September 2012) to 10.5\% (9 July 2009), with an overall mean of $8.4 \% \pm 1.2$ (SD) (Table 1). Monthly percent overnight shrink values across the four years were $8.7 \%( \pm 1.3 \mathrm{SD})$ for June, $8.7 \%( \pm 1.7 \mathrm{SD})$ for July, $9.0 \%( \pm 1.0 \mathrm{SD})$ for August, and $7.1 \%( \pm 1.3 \mathrm{SD})$ for September. Lower percent overnight shrink in September is likely due to more mature forage during this month (and less greenness as reflected in the NDVI values), which slows gut passage rates.

The best fit prediction model for percent overnight shrink across the 16 weighings was robust (explained $80 \%$ of the variance $^{\text {ii }}$ ) and included NDVI ${ }^{\text {iii }}$ and average air temperature, ${ }^{\text {iv }}$

\footnotetext{
ii $\mathrm{r}^{2}=0.80$.

iii $\mathrm{P}<0.0001$.

iv $\mathrm{P}=0.0002$.
}

but not average relative humidity. The prediction equation resulting from the best model was:

$\mathrm{y}$ (percent overnight shrink)

$=0.13+(10.56 *$ NDVI value $)$

$+\left(0.25 *\right.$ average air temperature in $\left.{ }^{\circ} \mathrm{C}\right)$

\section{Management Implications}

Our hypothesis that percent overnight shrink would be increased by higher air temperatures, lower relative humidity, and higher NDVI values (indicative of greener vegetation conditions) was partially supported. Percent overnight shrink by yearling steers grazing semiarid rangeland was influenced by air temperature and NDVI values, but not relative humidity. The thermal environment can affect production efficiency in livestock ${ }^{15,16}$ as the rate of respiration is highly correlated with body temperature. ${ }^{17}$ The finding that NDVI values are influential in affecting percent overnight shrink for yearling steers in semiarid rangelands are novel. This NDVI effect is likely related to steers having fuller gastrointestinal 
tract from the increased availability of forage with higher moisture content as indicated by higher NDVI values.

Our findings for percent overnight shrink values from crossbred yearling steers in this 4-year study (mean value of $8.4 \%$ across the 16 weighings) are in close agreement with estimates of shrink of $7.5-8.5 \%$ for a 17 -hour period using regression equations derived from cows in a semiarid northwestern Texas rangeland. ${ }^{3}$ Our percent overnight shrink values are also similar to the 6-9\% shrink estimates for 24-hour periods in drylots. ${ }^{18-20}$

Determination of periodic weight gains for grazing studies has previously been problematic, as free-ranging livestock needed to be gathered and confined overnight in corrals prior to weighing to get shrunk weights. The prediction equation from this study for semiarid rangelands provides a robust quantification of this overnight percent shrink across the grazing season using effects of air temperature and NDVI values. Use of this prediction equation can provide temporal weight gain data within a grazing season without the logistical difficulties in gathering and holding animals, as well as eliminate associated animal stress from shrinking and regaining gut fill multiple times.

\section{Acknowledgments}

We thank Crow Valley Livestock Cooperative, Inc. for providing livestock throughout the duration of this study. Data collection efforts by Mary Ashby, Jeff Thomas, Tammy Kanode, Troy Smith, Todd Erickson, Cody Jensen, Kayla Bish, Alicia Komloski, Amanda Van Pelt, Jacy Pannell, and Austin Steel are appreciated.

\section{References}

1. Carstens, G.E., D.E. Johnson, M.A. Ellenberger, and J.D. TAtum. 1991. Physical and chemical components of the empty body during compensatory growth in beef steers. Journal of Animal Science 69:3251-3264.

2. Aiken, G.E., And S.F. Tabler. 2004. Technical note: influence of fasting time on body weight shrinkage and average daily gain. Professional Animal Scientist 20:524-527.

3. Heitschmidt, R.K. 1982. Diurnal variation in weight and rates of shrink of range cows and calves. Journal of Range Management 35:717-720.

4. Phillips, W.A., P.E. Juniewicz, And D.L. VonTungeln. 1991. The effect of fasting, transit plus fasting, and administration of adrenocorticotropic hormone on the source and amount of weight lost by feeder steers of different ages. Journal of Animal Science 69:2342-2348.

5. Watson, A.K., B.L. Nuttelman, T.J. Klopfenstein, L.W. Lomas, AND G.E. ERICKSON. 2013. Impacts of a limit-feeding procedure on variation and accuracy of cattle weights. Journal of Animal Science 91:5507-5517.

6. Paruelo, J.M., H.E. Epstein, W.K. Lauenroth, and I.C. BuRKE. 1997. ANPP estimates from NDVI for the central grassland region of the US. Ecology 78:953-958.
7. Been, O., R. Phillips, J. Hendrickson, A.B. Frank, and S. KRONBERG. 2007. Estimating forage quantity and quality using aerial hyperspectral imagery for northern mixed-grass prairie. Remote Sensing of Environment 110:216-225.

8. Adams, D.C., P.O. Currie, B.W. Knapp, T. Mauney, and D. RiCHARDSON. 1987. An automated range-animal data acquisition system. Journal of Range Management 40:256-258.

9. Anderson, D.M., And D.L. Weeks. 1989. Cattle liveweight sampled on a continuous versus intermittent basis. Livestock Production Science 23:117-135.

10. Hart, R.H., And M.M. Ashby. 1998. Grazing intensities, vegetation, and heifer gains: 55 years on shortgrass. Journal of Range Management 51:392-398.

11. Milchunas, D.G., J.R. Forwood, and W.K. Lauenroth. 1994. Productivity of long-term grazing treatments in response to seasonal precipitation. Journal of Range Management 47:133-139.

12. Grandin, T. 1998. Review: Reducing handling stress improves both productivity and welfare. Professional Animal Scientist 14:110.

13. Coffey, K.P., F.K. Brazle, J.J. Higgins, and J.L. Moyer. 1997. Effects of gathering time on weight and shrink of steers grazing smooth bromegrass pastures. Professional Animal Scientist $13: 170-175$.

14. Grandin, T. 1990. Design of loading facilities and holding pens. Applied Animal Behavior Science 28:187-201.

15. Ames, D. 1980. Thermal environment affects production efficiency of livestock. BioScience 30:457-460.

16. Silanikove, N. 2000. Effects of heat stress on the welfare of extensively managed domestic ruminants. Livestock Production Science 67:1-18.

17. Hahn, G.L. 1999. Dynamic responses of cattle to thermal heat loads. Journal of Animal Science 77:10-20.

18. Whiteman, J.V., P.F. Loggins, D. Chambers, L.S. Pope, and D.F. STEPHEns. 1954. Some sources of error in weighing steers off grass. Journal of Animal Science 13:832-842.

19. Hughes, J.G. 1976. Short-term variation in animal live weight and reduction of its effect on weighing. Animal Breeding Abstracts 44:111-118.

20. Wythes, J.R., W.R. Shorthose, P.J. Schmidt, and C.B. DAvIs. 1980. Effects of various rehydration procedures after a long journey on liveweight carcasses and muscle properties of cattle. Australian Journal of Agricultural Research 31:849-855.

Authors are Rangeland Scientist and Research Leader (Derner, Justin.Derner@ars.usda.gov),Post-doctoral Research Associate (Reeves) and Physical Science Technician (Mortenson), US Dept of Agriculture-Agricultural Research Service-Rangeland Resources Research Unit, Cheyenne, WY 82009, USA; Area Statistician US Dept of Agriculture-Agricultural Research Service-Plains Area, Fort Collins, CO 80526, USA (West); Agronomist Cátedra de Forrajicultura, IFEVA, Facultad de Agronomía, Universidad de Buenos Aires, CONICET, C1417DSE, Buenos Aries, Argentina (Isisarri); and Agronomist, Instituto Nacional de Tecnología Agropecuaria (INTA), Estación Experimental Concepción del Uruguay, Entre Ríos, Argentina (Durante). Funding was provided by the USDA-ARS. 